\title{
Efecto de Temperatura y Tiempo de Almacenamiento de Ovarios de Alpacas sobre la Tasa de Maduración y División in vitro de Ovocitos
}

\author{
Effect of Temperature and Time of Storage of Alpaca Ovaries on in vitro \\ Maturation and Cleavage Rate of Oocytes
}

\author{
Irma Arriaga C. ${ }^{\text {, Wilfredo Huanca L., }}$, Marino Terreros C. ${ }^{1}$, Juan J. Becerra G. ${ }^{3}$, \\ Pedro García H. ${ }^{3}$, Antonio Ampuero B. ${ }^{2}$
}

\section{Resumen}

Se evaluó el efecto de la temperatura $\left(12-15\right.$ y $\left.22-25^{\circ} \mathrm{C}\right)$ y el tiempo de almacenamiento (0 y 16 horas) de ovarios de alpacas sobre la tasa de maduración y división posfecundación in vitro. Los ovarios fueron recolectados de alpacas adultas sacrificadas en el camal de Pilpichaca (Huancavelica, Perú) y transportados al laboratorio en solución salina al $0.9 \%$ con una temperatura inicial de $35^{\circ} \mathrm{C}$. Los ovarios fueron distribuidos al azar en los tratamientos Control $(0 \mathrm{~h}), \mathrm{T} 1\left(16 \mathrm{~h}\right.$ a $\left.12-15^{\circ} \mathrm{C}\right)$ y T2 $\left(16 \mathrm{~h} \mathrm{a} 22-25^{\circ} \mathrm{C}\right)$. Los ovocitos se obtuvieron por disección, seleccionándose aquellos con una o más capas de cúmulos, y madurados en medio TCM 199 por $40 \mathrm{~h}$ bajo condiciones de $5 \% \mathrm{CO}_{2}$ y $39{ }^{\circ} \mathrm{C}$. Parte de los ovocitos (172) fueron fijados y teñidos para evaluar el estadio de maduración nuclear y los restantes (440) fueron co-cultivados por $18 \mathrm{~h}$ con espermatozoides obtenidos de epidídimos. Posteriormente, los presuntos cigotos fueron colocados en medio de cultivo KSOM por $72 \mathrm{~h}$ posfecundación in vitro y luego transferidos a medio SOF. Se obtuvo una tasa de maduración nuclear en metafase II de 47.9, 12.2 y 32.7\%, una tasa de división de $46.2,8.1$ y $32.7 \%$ y una tasa de blastocistos de $33.3,14.2$ y $20.6 \%$ para los grupos Control, $\mathrm{T} 1$ y T2, respectivamente ( $\mathrm{p}<0.05$, excepto entre la tasa de blastocistos del T1 y T2). Los resultados sugieren que el almacenamiento de ovarios de alpaca a $22-25^{\circ} \mathrm{C}$ por $16 \mathrm{~h}$ (T2) permite mantener la calidad de los ovocitos y obtener una mayor tasa de maduración y de división posfecundación in vitro.

Palabras clave: temperatura, almacenamiento de ovarios, ovocitos, fecundación in vitro, alpacas

\footnotetext{
${ }^{1}$ Laboratorio de Reproducción Animal, ${ }^{2}$ Laboratorio de Zootecnia y Producción Agropecuaria, Facultad de Medicina Veterinaria, Universidad Nacional Mayor de San Marcos, Lima, Perú

${ }^{3}$ Departamento de Patología Animal, Unidad de Reproducción Animal, Universidad Santiago de Compostela, España

${ }^{3}$ E-mail: whuanca2002@yahoo.com
}

Recibido: 20 de diciembre de 2013

Aceptado para publicación: 12 de agosto de 2014 
The present study evaluated the effect of temperature $\left(12-15\right.$ and $\left.22-25^{\circ} \mathrm{C}\right)$ and the time of storage ( 0 and 16 hours) in ovaries of alpacas on the maturation and cleavage rate post in vitro fertilization. The ovaries were collected from slaughtered mature alpacas at Pilpichaca slaughterhouse (Huancavelica, Peru) and transported to the laboratory in $0.9 \%$ saline solution with an initial temperature of $35^{\circ} \mathrm{C}$. The ovaries were randomly distributed in three groups: Control $(0 \mathrm{~h}), \mathrm{T} 1\left(16 \mathrm{~h}\right.$ at $\left.12-15^{\circ} \mathrm{C}\right)$ and $\mathrm{T} 2\left(16 \mathrm{~h}\right.$ at $\left.22-25^{\circ} \mathrm{C}\right)$. The oocytes were recovered by slicing of the ovaries and only oocytes with one or more layers of cumulus were selected and cultured in maturation medium TCM-199 for $40 \mathrm{~h}$ under $5 \% \mathrm{CO}_{2}$ at $39^{\circ} \mathrm{C}$. Part of the oocytes (172) were fixed and dyed to evaluate the stage of nuclear maturation and the rest (440) were co-incubated for $18 \mathrm{~h}$ with sperm obtained from epididymis. Later on, the presumed zygotes were placed in KSOM culture medium for $72 \mathrm{~h}$ post in vitro fertilization and then transferred to SOF medium. The results showed a nuclear maturation rate in metaphase II of 47.9, 12.2, and 32.7\%; a cleavage rate of 46.2, 8.1, and $32.7 \%$; and a blastocyst rate of 33.3, 14.2, and 20.6\% for the Control, T1 and T2 groups respectively ( $\mathrm{p}<0.05$, except for blastocyst rate in $\mathrm{T} 1$ and $\mathrm{T} 2)$. The results suggested that ovaries of alpaca stored at $22-25^{\circ} \mathrm{C}$ for $16 \mathrm{~h}$ (T2) would maintain the oocytes quality and allow better maturation and cleavage rate post in vitro fertilization.

Key words: temperature, ovaries storage, oocytes, in vitro fertilization, alpaca

\section{INTRODUCCIÓN}

En especies domésticas de interés económico, como en el bovino, se emplean biotecnologías reproductivas para contribuir a la mejora genética animal; sin embargo, estudios sobre biotecnología reproductiva en camélidos sudamericanos (CSA) son muy limitados (Miragaya et al., 2006), habiendo algunas experiencias en inseminación artificial y transferencia de embriones. No obstante, la fecundación in vitro (FIV) es una tecnología alternativa y factible de ser aplicada en los programas de mejoramiento genético, y para los que se requieren gametos de hembras con adecuado potencial genético.

El éxito de un protocolo de FIV requiere controlar el tiempo de transporte, así como el tiempo y temperatura de almacenamiento de los ovarios, sin afectar la calidad y competencia de los ovocitos y su desarrollo (Taş et al., 2006; Huanca et al., 2007; Ribeiro et $a l ., 2008)$, de modo de asegurar la viabilidad y capacidad de maduración in vitro (MIV) y posterior desarrollo embrionario. Tiempo y temperatura son dos factores claves que pueden contribuir a los efectos perjudiciales en la calidad del ovocito, en términos de maduración nuclear y tasas de división posterior a la FIV (Klumpp, 2004).

Existen diversas investigaciones para el bovino sobre el efecto de la temperatura de transporte y del tiempo de almacenamiento de ovarios sobre la calidad de los ovocitos (Yang et al., 1990; Sirard y Blondin, 1996; Blondin et al., 1997; Schernthaner et al., 1997; Matsushita et al., 2004). En líneas generales, los ovarios del bovino son recuperados entre 1 a 2 horas del sacrificio del animal y colocados a una temperatura de $30^{\circ} \mathrm{C}$, donde los ovocitos son obtenidos en el menor tiempo posible (Gordon, 2003).

En ovarios de equinos almacenados por 22-24 h a $15-20{ }^{\circ} \mathrm{C}$ se llegó a obtener una tasa de metafase II (MII) de $38.5 \%$, de división de $48.7 \%$ y de blastocistos de $7.7 \%$, indi- 
cando que los ovocitos inmaduros almacenados por un día mantuvieron su competencia de desarrollo in vitro (Matsukawa et al., 2007). Asimismo, se ha logrado obtener gestaciones con ese tipo de ovocitos (Preis et al., 2004).

La proporción de ovocitos de camellos dromedarios que alcanzaron la etapa de MII de los ovarios colectados y almacenados en solución salina normal (NSS) a temperatura ambiente por $12 \mathrm{~h}$ fue de $43 \%$, y sin diferencias estadísticas con ovarios transportados en NSS tibia y procesados inmediatamente a su llegada al laboratorio; sin embargo, la tasa de MII fue menor (29\%) cuando estos últimos fueron almacenados a temperatura ambiente (Wani y Nowshari, 2005).

El transporte de ovarios porcinos almacenados entre $25-35^{\circ} \mathrm{C}$ por 6 horas mantiene la competencia de los ovocitos en la MIV, pero las tasas de conservación son menores en comparación a un tiempo de transporte de 3 horas (Wongsrikeao et al., 2005). La autolisis celular ocurre en ovarios durante largos periodos de transporte a $35-38^{\circ} \mathrm{C}$ o cuando se hace a temperaturas de refrigeración (Holt y Pickard, 1999), aunque hay reportes de buenos resultados de MIV de ovocitos de ovarios felinos que fueron transportados y almacenados a $4{ }^{\circ} \mathrm{C}$ (Wolfe y Wildt, 1996). Estudios más recientes concluyen que la recuperación y transporte de ovarios a $4{ }^{\circ} \mathrm{C}$ se debe realizar en menos de 6 horas del sacrificio (Naoi et al., 2007).

En el caso de camélidos sudamericanos, y específicamente en la alpaca, no existen reportes sobre el efecto de la temperatura y tiempo de almacenamiento de ovarios en la tasa de maduración in vitro, fecundación in vitro y cultivo in vitro (CIV). Por otro lado, teniendo en cuenta que los centros de sacrificio ubicados en zonas altoandinas como Puno, Cusco, Arequipa, Huancavelica y Ayacucho se encuentran alejados de los laboratorios de reproducción, se requiere evaluar el efecto del tiempo y temperatura de almacenamiento previo a la obtención de los ovocitos.

\section{Materiales y Métodos}

\section{Lugar de Estudio}

Se recolectaron 202 ovarios de alpacas en el camal de Pilpichaca (provincia de Huaytará, departamento de Huancavelica) entre febrero y junio de 2010. La historia reproductiva de los animales era desconocida. El procesamiento de las muestras se llevó a cabo en la sección de Biotecnología Reproductiva del Laboratorio de Reproducción Animal de la Facultad de Medicina Veterinaria, Universidad Nacional Mayor de San Marcos (FMV-UNMSM), Lima, Perú, y la tinción y lectura de los ovocitos fijados se llevó a cabo en la Unidad de Reproducción y Obstetricia de la Facultad de Veterinaria, Universidad de Santiago de Compostela, Lugo, España.

Los ovarios se recolectaron directamente del tracto reproductor de los animales luego del sacrificio. Se colocaron en un termo que contenía solución salina a $0.9 \%(\mathrm{NaCl})$, con una temperatura inicial de $35^{\circ} \mathrm{C}$. El traslado al laboratorio duró aproximadamente 8 horas, donde llegaron con una temperatura promedio de $24{ }^{\circ} \mathrm{C}$. Una vez en el laboratorio, los ovarios fueron distribuidos al azar en los tres grupos experimentales.

\section{Diseño Experimental}

Los ovarios fueron distribuidos en tres tratamientos en forma aleatoria, en base a un diseño completamente randomizado (Fig. 1), según se señala a continuación:

C: $8 \mathrm{~h}$ de transporte y $0 \mathrm{~h}$ de almacenamiento

T1: $8 \mathrm{~h}$ de transporte y $16 \mathrm{~h}$ de almacenamiento a $12-15^{\circ} \mathrm{C}$

T2: $8 \mathrm{~h}$ de transporte y $16 \mathrm{~h}$ de almacenamiento a $22-25{ }^{\circ} \mathrm{C}$

Además, el estudio comprendió dos fases: 
Fase 1: Se evaluó la tasa de maduración nuclear in vitro de ovocitos (Metafase II) para los tres grupos, con tres réplicas por tratamiento.

Fase 2: Se evaluó la tasa de división de ovocitos a las $72 \mathrm{~h}$ posfecundación in vitro y la tasa de blastocistos a los siete días posfecundación in vitro para los tres grupos, con cinco réplicas por tratamiento.

\section{Obtención y Selección de los Ovocitos}

Los ovarios se lavaron con solución salina para eliminar el exceso de sangre. Se removió el tejido circundante al ovario y se procedió a la disección (slicing) de cada folículo ovárico (2 a $6 \mathrm{~mm}$ de diámetro) sobre una placa Petri con medio de lavado premaduración. Luego de repetidos cortes, se vertió $0.2 \mathrm{ml}$ del medio de lavado para recuperar el líquido folicular y poder depositar el mayor número de complejo cúmulus-ovocitos (CCOs). Se dejó reposar por 10 minutos (Rivera et al., 2010).

Con la ayuda de un estereomicroscopio, se localizaron los CCOs, seleccionándose los ovocitos con una o más capas completas de células del cúmulus no expandidas con aspecto compacto, y citoplasma homogéneo y granulado, frente a ovocitos parcial o completamente denudados (Lorenzo, 1992; Blon- din y Sirard, 1995; Hinrichs y Williams, 1997), correspondiendo a los grados 1 a 3 según la clasificación de Bertoldo et al. (2010) y Madison et al. (1992).

\section{Maduración in vitro}

Los ovocitos seleccionados fueron lavados tres veces con medio de lavado premaduración para eliminar restos de cúmulus y tejido ovárico. Luego fueron colocados en grupos de 20 ovocitos por microgota de medio de maduración TCM-199 suplementado con FSH, y madurados en la incubadora bajo condiciones de $39{ }^{\circ} \mathrm{C}$ con $5 \%$ de $\mathrm{CO}_{2}, 20 \%$ de $\mathrm{O}_{2}$ y humedad relativa alta durante 20 horas. Luego fueron transferidos a microgotas de medio de maduración sin FSH y madurados por otras 20 horas bajo las condiciones descritas.

Cumplido el tiempo de maduración, se eliminaron las células del cúmulus mediante la agitación en vortex y se fijaron en etanol ácido acético (3:1), por no menos de 36 horas a $4{ }^{\circ} \mathrm{C}$ en refrigeración. Se retiraron los ovocitos de la solución de fijación y se colocaron entre 5 a 10 por portaobjeto cubierto con un cubreobjeto adherido con parafinavaselina (1:1). Se adicionó orceína (1\% de orceína disuelta en ácido acético al $45 \%$ ) por un extremo del cubreobjeto para teñir los ovocitos, dejándose secar por 20 minutos. Por

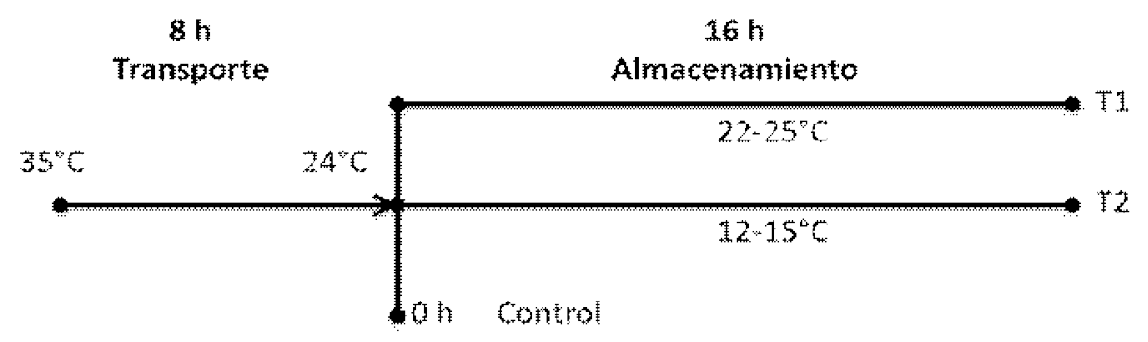

Figura 1. Diseño experimental 
último, se sellaron con laca de uñas y se evaluaron en un microscopio de contraste de fase a 400X, determinando la fase de maduración nuclear en las que se encontraban los ovocitos: vesícula germinal (VG), metafase I (MI), anafase-telofase I, metafase II (MII) $\mathrm{y}$ degenerados.

\section{Colección de Espermatozoides Epididi- marios}

Se obtuvieron testículos de alpacas machos adultos, sacrificadas en el mismo camal, y fueron colocados en tampón fosfato salino (PBS) para su transporte. Una vez en el laboratorio, los testículos fueron lavados, desinfectados y divulsionados para obtener las colas de los epidídimos. Estas fueron diseccionadas mientras se añadía una solución de TRIS-yema de huevo temperada a $37{ }^{\circ} \mathrm{C}$. Se encontró una concentración de $190 \times 10^{6}$ espermatozoides $/ \mathrm{ml}, 70 \%$ de motilidad espermática y $51 \%$ de funcionalidad de membrana espermática en promedio. Las muestras fueron refrigeradas hasta el momento de la fecundación in vitro.

\section{Fecundación in vitro}

Cumplido el periodo de maduración de los ovocitos y de observar la expansión del cúmulus (Gordon, 2003), se lavaron los ovocitos de cada tratamiento por separado con medio de pre-fecundación, para luego ser colocados en grupos de 20 en microgotas de Medio de fecundación TL-stock, por no menos de una hora.

Los espermatozoides fueron separados mediante una gradiente discontinua de Percoll de $22.5 \%: 45 \%$, la que se centrifugó por 10 minutos a $600 \mathrm{G}$ y luego por 5 minutos a $300 \mathrm{G}$ El pellet obtenido fue reconstituido con $30 \mu \mathrm{l}$ de TL-Stock.

Finalmente, se colocaron $2 \mu \mathrm{l}$ de suspensión de espermatozoides en cada microgota con los ovocitos maduros y se añadieron $2 \mu 1$ de heparina al $2 \%$ y $2 \mu 1$ de PHE (2 mM Penicilamina, $1 \mathrm{mM}$ Hipotaurina y 250
mM Epinefrina). Se realizó el co-cultivo en una estufa bajo condiciones de $39^{\circ} \mathrm{C}$ con $5 \%$ de $\mathrm{CO}_{2}, 20 \%$ de $\mathrm{O}_{2}$ y humedad relativa alta durante 18 horas.

\section{Cultivo in vitro}

Cumplido el tiempo de co-cultivo de gametos, se retiraron los presuntos cigotos para eliminar las células del cúmulus y los espermatozoides adheridos a la zona pelúcida mediante agitación por vortex durante $5 \mathrm{mi}$ nutos. Los presuntos cigotos de cada tratamiento fueron lavados por separado con medio de lavado Pre-cultivo SOF-Hepes y colocados en microgotas de medio cultivo KSOMAA. Luego fueron cultivados por $72 \mathrm{~h}$ y se evaluó el desarrollo embrionario temprano (28 células) mediante la tasa de división (Khatir et al., 2007). Luego fueron transferidos a medio de cultivo SOF-Stock, donde permanecieron hasta los siete días posfecundación para proceder a evaluar el porcentaje de blastocistos.

\section{Análisis Estadístico}

Los resultados fueron expresados como porcentajes y distribuidos para cada grupo experimental. Al tratarse de datos cualitativos, se utilizó una prueba no paramétrica de Chicuadrado de Pearson. En el análisis de los datos se utilizó el programa SPSS v. 15.

\section{Resultados}

En la evaluación de la maduración nuclear in vitro se utilizaron 71 ovarios y en la evaluación de la división posfecundación in vitro se emplearon los 131 ovarios restantes. En total se obtuvieron 1571 ovocitos de 1813 folículos diseccionados (slicing). Se seleccionaron 172 ovocitos de buena calidad para la evaluación de la maduración nuclear in vitro y 452 ovocitos de buena calidad para la evaluación de la división pos-fecundación in vitro. En este último experimento se perdieron 12 ovocitos, quedando 440 ovocitos madurados para que entren a la FIV/CIV. 
Cuadro 1. Tasa de maduración nuclear (Metafase II) de ovocitos colectados de ovarios de alpacas sacrificadas en el camal de Huancavelica, Perú ${ }^{1}$

\begin{tabular}{|c|c|c|c|c|}
\hline & Tratamiento & $\mathrm{N}^{\circ}$ ovarios & Metafase II & $\begin{array}{l}\text { Total ovocitos } \\
\text { (n) }\end{array}$ \\
\hline $\mathrm{C}$ & $(0 \mathrm{~h})$ & 26 & $47.9 \%^{\mathrm{a}}$ & 71 \\
\hline $\mathrm{T} 1$ & $\left(16 \mathrm{~h}, 12-15^{\circ} \mathrm{C}\right)$ & 24 & $12.2 \%^{\mathrm{b}}$ & 49 \\
\hline $\mathrm{T} 2$ & $\left(16 \mathrm{~h}, 22-25^{\circ} \mathrm{C}\right)$ & 21 & $32.7 \%^{\mathrm{c}} \quad(17)$ & 52 \\
\hline & Total & 71 & $33.1 \% \quad(57)$ & 172 \\
\hline
\end{tabular}

Cuadro 2. Tasa de división a las 72 horas posfecundación in vitro y tasa de blastocistos a los siete días posfecundación in vitro en alpacas a partir de 440 ovocitos colectados de ovarios de alpacas sacrificadas en el camal de Huancavelica, Perú $^{1}$

\begin{tabular}{|c|c|c|c|c|c|}
\hline & Tratamiento & $\begin{array}{c}\text { Ovarios } \\
(\mathrm{n})\end{array}$ & $\begin{array}{c}\text { División } \\
72 \mathrm{~h} \\
\end{array}$ & $\begin{array}{c}\text { Blastocistos } \\
7 \text { días }\end{array}$ & $\begin{array}{l}\text { Total de ovocitos } \\
\text { (n) }\end{array}$ \\
\hline $\mathrm{C}$ & $(0 \mathrm{~h})$ & 26 & $46.2 \%^{\mathrm{a}}(43)$ & $33.3 \%^{\mathrm{a}}(31)$ & $100 \%(93)$ \\
\hline $\mathrm{T} 1$ & $\left(16 \mathrm{~h}, 12-15^{\circ} \mathrm{C}\right)$ & 50 & $8.1 \%^{\mathrm{b}}(12)$ & $14.2 \%^{\mathrm{b}}(21)$ & $100 \%(148)$ \\
\hline $\mathrm{T} 2$ & $\left(16 \mathrm{~h}, 22-25^{\circ} \mathrm{C}\right)$ & 55 & $32.7 \%^{\mathrm{c}}(65)$ & $20.6 \%^{\mathrm{b}}(41)$ & $100 \%$ (199) \\
\hline & Total & 131 & $27.3 \%(120)$ & $21.1 \%(93)$ & $100 \%(440)$ \\
\hline
\end{tabular}

Los resultados de la maduración nuclear en MII a las 40 horas de MIV se muestran en el Cuadro 1. Se evidencia que la tasa de MII en el tratamiento de mayor temperatura (T2) fue superior a T1 $(\mathrm{p}<0.05)$, mientras que el Control $(0 \mathrm{~h})$ fue superior a los otros dos grupos de almacenamiento $(16 \mathrm{~h})$ $(\mathrm{p}<0.05)$.
La tasa de división a las $72 \mathrm{~h}$ de la fecundación in vitro y la tasa de blastocistos a los siete días de la fecundación in vitro se resumen en el Cuadro 2. Al igual que en el caso de la maduración nuclear, T2 obtuvo mejores resultados de división embrionaria que T1, aunque no estadísticamente diferentes, mientras que el Control $(0 \mathrm{~h})$ fue supe- 
rior a los otros dos grupos de almacenamiento $(16 \mathrm{~h})(\mathrm{p}<0.05)$.

Todos los blastocistos presentaron como característica constante la presencia de una coloración oscura, producto de la presencia de lípidos citoplasmáticos.

\section{Discusión}

Esta es la primera experiencia que evalúa la influencia de la temperatura y el tiempo de almacenamiento de los ovarios sobre la viabilidad de los ovocitos de alpaca para MIV/FIV/CIV en alpacas en el país. Temperaturas de $12-15{ }^{\circ} \mathrm{C}$ con $16 \mathrm{~h}$ de almacenamiento permitieron una tasa de maduración de $12.2 \%$, una tasa de división a las 72 h de la fecundación de $8.1 \%$ y una tasa de blastocistos de $14.2 \%$ a los 7 días de la fecundación.

En una experiencia similar en bovinos, donde se mantuvieron ovarios a $10^{\circ} \mathrm{C}$ por 24 horas, se obtuvo una tasa de maduración de $68 \%$, de división en la etapa de mórula de $33 \%$ y de blastocistos de 25\% (Matsushita et al., 2004). Asimismo, Wang et al. (2011) concluyeron que el almacenamiento a $15{ }^{\circ} \mathrm{C}$ por un periodo de 3 a $4 \mathrm{~h}$ tenía un efecto benéfico significativo en la calidad y competencia de desarrollo de ovocitos usados para la transferencia nuclear de células somáticas (SCNT), debido al alivio del estrés en el ovocito, comparado con los ovarios sujetos a temperaturas de almacenamiento de 25 o $35^{\circ} \mathrm{C}$.

Al comparar estos estudios con la presente investigación, se evidencia que los ovarios de alpaca son susceptibles al almacenamiento en temperaturas de 12 a $15^{\circ} \mathrm{C}$ y que la competencia del ovocito para FIV se ve disminuida. Esta situación se asemeja a otros estudios donde se reportaron bajas tasas de división y formación de blastocistos cuando los ovarios fueron guardados a $4{ }^{\circ} \mathrm{C}$ (Yang et al., 1990) o $10{ }^{\circ} \mathrm{C}$ (Shigeki y Yasuo, 1993, citado porWani y Nowshari, 2005). Esto puede ser posible debido a que la membrana lipídica de los ovocitos bovinos sufría cambios cuando se exponía a temperaturas inferiores a $20{ }^{\circ} \mathrm{C}$ (Arav et al., 1996); así como lesiones del huso meiótico y endurecimiento de la zona pelúcida que afectaba directamente la fecundación (Wlodarczyk et al., 2009). Sin embargo, la fase de transición lipídica no ha sido examinada para los ovocitos de alpaca.

En el presente estudio se evidencia que la tasa de blastocistos (14.2\%) aumenta con respecto a la tasa de división $(8.1 \%)$, posiblemente debido a la baja temperatura de almacenamiento de los ovarios, dado que las actividades metabólicas de los ovocitos disminuyen con las bajas temperaturas; sin embargo, con el avance del tiempo de cultivo se pudo observar mayor cantidad de ovocitos divididos y que alcanzaron la etapa de blastocistos.

En el caso del tratamiento con mayor temperatura de almacenamiento $\left(22-25^{\circ} \mathrm{C}\right)$, se obtuvo una tasa de maduración de $32.7 \%$, de división a las $72 \mathrm{~h}$ de la fecundación de $32.7 \%$ y de blastocistos a los 7 días de la fecundación de $20.6 \%$. En investigaciones similares en el camello dromedario, donde los ovarios fueron almacenados a temperatura ambiente por $12 \mathrm{~h}$ y donde la proporción de ovocitos que alcanzaron la etapa de MII fue de $43 \%$ (Wani y Nowshari, 2005), se puede observar que los resultados fueron similares, lo que sugiere que la temperatura ambiente juega un papel importante en la viabilidad de los ovocitos de alpaca, demostrado por las buenas tasas de MIV/CIV, comparado con temperaturas más bajas $\left(12-15^{\circ} \mathrm{C}\right)$. Esta conclusión llega a ser relevante cuando se considera el transporte y almacenamiento de ovarios para fines de investigación o de uso comercial.

En la especie bovina se han realizado estudios que avalan lo mencionado anteriormente. Schernthaner et al. (1997) demostraron que era posible almacenar los ovarios a $15-21^{\circ} \mathrm{C}$ hasta $12 \mathrm{~h}$ antes de la maduración, sin afectar adversamente la competencia de 
desarrollo de los ovocitos. Además, Yang et al. (1990) sugirieron que los ovarios bovinos pueden ser almacenados a $25^{\circ} \mathrm{C}$ por $16 \mathrm{~h}$, sin reducir la habilidad del ovocito para ser fecundado y desarrollado hasta la etapa de blastocisto. En equinos se almacenaron ovarios por $22-24 \mathrm{~h}$ a $15-20{ }^{\circ} \mathrm{C}$ y se logró obtener tasa de MII de $38.5 \%$, de división de 48.7\% y de blastocistos de $7.7 \%$ (Matsukawa et al., 2007); asimismo, en otro experimento se lograron gestaciones a partir de ovocitos MIV recuperados de ovarios almacenados por $18-24$ h a 12 y $22{ }^{\circ} \mathrm{C}$ (Preiset al., 2004). Por otro lado, en ovarios de ovejas almacenados a $20-22{ }^{\circ} \mathrm{C}$ por $12 \mathrm{~h}$ se obtuvieron resultados similares que en ovarios no sometidos a largos periodos de almacenamiento (García Álvarez et al., 2011).

Todas estas experiencias en varias especies corroboran la mejor viabilidad de ovocitos provenientes de ovarios almacenados a temperatura ambiente $\left(22-25^{\circ} \mathrm{C}\right)$, así como en la alpaca, a la vez que se reafirma la importancia de esta variable en el desarrollo de protocolos de FIV en alpacas.

\section{Conclusiones}

- El almacenamiento de ovarios de alpaca a $22-25^{\circ} \mathrm{C}$ por $16 \mathrm{~h}$ permitió obtener una mayor calidad y tasa de maduración nuclear (Metafase II) in vitro de los ovocitos $(\mathrm{p}<0.05)$ y una mayor tasa de división de ovocitos a las $72 \mathrm{~h}$ de la fecundación in vitro $(\mathrm{p}<0.05)$, en comparación con el mantenimiento de ovarios a $12-15{ }^{\circ} \mathrm{C}$.

- No se encontraron diferencias estadísticas entre las tasas de blastocistos debido al almacenamiento de ovarios de alpaca por $16 \mathrm{~h}$ a $22-25^{\circ} \mathrm{C}$ o a $12-15^{\circ} \mathrm{C}$.

- Se obtuvo una mayor tasa de maduración, división de ovocitos y tasa de blastocistos in vitro con $0 \mathrm{~h}$ de almacenamiento, en comparación con $16 \mathrm{~h}$ de almacenamiento de los ovarios $(\mathrm{p}<0.05)$.

\section{Agradecimientos}

Un especial agradecimiento al Proyecto $\mathrm{N}^{\circ} 064$ FINCyT-PIBAP 2008 por el financiamiento para el desarrollo del presente trabajo.

\section{Literatura Citada}

1. Arav A, Zeron Y, Leslie SB, Behboodi E, Anderson GB, Crowe JH. 1996. Phase transition temperature and chilling sensitivity of bovine oocytes. Cryobiology 33:589-599.

2. Bertoldo M, Holyoake PK, Evans G, Grupen CG. 2010. Oocyte developmental competence is reduced in sows during the seasonal infertility period. Reprod Fert Develop 22: 1222-1229. doi: 10.1071/RD10093

3. Blondin P, Coenen K, Guilbault LA, Sirard MA. 1997. In vitro production of bovine embryos: Developmental competence is acquired before maturation. Theriogenology 47: 10611075.

4. Blondin P, Sirard MA. 1995. Oocyte and follicular morphology as determining characteristics for developmental competence in bovine oocytes. Mol Reprod Dev 41: 54-62.

5. García-Álvarez O, Maroto-Morales A, Berlinguer F, Fernández-Santos MR, Esteso MC, Mermillod P, Ortiz JA, et al. 2011. Effect of storage temperature during transport of ovaries on in vitro embryo production in Iberian red deer (Cervuselaphus hispanicus). Theriogenology 75: 65-72. doi: 10.1016/ j.theriogenology.2010.07.011

6. Gordon I. 2003. Laboratory production of cattle embryos. $2^{\text {nd }}$ ed. Wallingford: CABI International. 548 p.

7. Hinrichs K, Williams KA. 1997. Relationships among oocyte-cumulus morphology, follicular atresia and oocyte meiotic competence in the horse. Biol Reprod 57: 377-384. 
8. Holt WV, Pickard AR. 1999. Role of reproductive technologies and genetic resource banks in animal conservation. Rev Reprod 4: 143-150.

9. Huanca W, Palomino JM, Cervantes M, Cordero A, Huanca T. 2007. Efecto de temperaturas de transporte $\left(35{ }^{\circ} \mathrm{C}, 4{ }^{\circ} \mathrm{C}\right)$ sobre la calidad morfológica de ovocitos colectados desde ovarios de alpacas. En: Res. XX Reunión ALPA. Cusco, Perú.

10. Khatir H, Anouassi A, Tibary A. 2007. Effect of follicular size on in vitro developmental competence of oocytes and viability of embryos after transfer in the dromedary (Camelus dromedarius). Anim Reprod Sci 99: 413-420.

11. Klumpp AM. 2004. The effect of holding bovine oocytes in follicular fluid on subsequent fertilization and embryonic development. MSc Thesis. USA: Louisiana State University. 120 p.

12. Lorenzo PL. 1992. Maduración in vitro de ovocitos de ganado vacuno. Tesis doctoral. España: Universidad Complutense de Madrid. $231 \mathrm{p}$.

13. Madison V, Avery B, Greve T. 1992. Selection of immature bovine oocytes for developmental potential in vitro. Anim Reprod Sci 27: 1-11.

14. Matsukawa K, Akagi S, Adachi N, Sato F, Hasegawa T, Takahashi S. 2007. In vitro development of equine oocytes from preserved ovaries after intracytoplasmic sperm injection. J Reprod Develop 53: 877-885.

15. Matsushita S, Tani T, Kato Y, Tsunoda Y. 2004. Effect of low-temperature bovine ovary storage on the maturation rate and developmental potential of follicular oocytes after in vitro fertilization, parthenogenetic activation, or somatic cell nucleus transfer. Anim Reprod Sci 84: 293-301.

16. Miragaya MH, Chaves MG, Agüero A. 2006. Reproductive biotechnology in South American Camelids. Small Ruminant Res 61: 299-310. doi: 10.1016/ j.smallrumres.2005.07.017
17. Naoi H, Otoi T, Shimamura T, Karja NW, Agung B, Shimizu R, Taniguchi M, Nagai T. 2007. Developmental competence of cat oocytes from ovaries stored at various temperature for $24 \mathrm{~h}$. J Reprod Dev 53: 271-277.

18. Preis KA, Carnevale ME, Coutinho da Silva MA, Caracciolo di Brienza V, Gomes GM, Maclellan LJ, Squires EL. 2004. In vitro maturation and transfer of equine oocytes after transport of ovaries at 12 or $22^{\circ} \mathrm{C}$. Theriogenology 61: 1215-1223.

19. Ribeiro BI, Love LB, Choi YH, Hinrichs $K$. 2008. Transport of equine ovaries for assisted reproduction. Anim Reprod Sci 108: 171-179.

20. Rivera RM, Bonilla L, Brad AM, Edwards JL, Ealy AD, Monterroso VM, Majewski AC, et al. 2010. Procedures for in vitro production of bovine embryos. Dep. of Animal Sciences, University of Florida. [Internet]. Available in: http:// www.animal.ufl.edu/hansen/IVF/ default.htm

21. Schernthaner W, Schmoll F, Brem G, Schellander K. 1997. Storing bovine ovaries for 24 hours between 15 and $21^{\circ} \mathrm{C}$ does not influence in vitro production of blastocysts. Theriogenology 47: 297.

22. Sirard MA, Blondin P. 1996. Oocyte maturation and IVF in cattle. Anim Reprod Sci 42: 417-426.

23. Tap M, Evecen M, Özdap Ö, Cirit $\ddot{U}$, Demir K, Birler S, Pabuccuoðlu S. 2006. Effect of transport and storage temperature of ovaries on in vitro maturation of bitch oocytes. Anim Reprod Sci 96: 30-34. doi: 10.1016/j.anireprosci.2005.11.001

24. Wang YS, Zhao X, Su JM, An ZX, Xiong XR, Wang LJ, Liu J, et al. 2011. Lowering storage temperature during ovary transport is beneficial to the developmental competence of bovine oocytes used for somatic cell nuclear transfer. Anim Reprod Sci 124: 48-54.doi: 10.1016/j.anireprosci.2011.01.015 
25. Wani NA, Nowshari MA. 2005. Kinetics of nuclear maturation and effect of holding ovaries at room temperature on in vitro maturation of camel (Camelus dromedarius) oocytes. Theriogenology 64: 75-85. doi: 10.1016/ j.theriogenology.2004.11.009

26. Wlodarczyk D, Bukowska D, Jackowska M, Mucha S, Jaskowski JM. 2009. In vitro maturation and degeneration of domestic cat oocytes collected from ovaries stored at various temperatures. Vet Med-Czech 54: 491-497.

27. Wolfe BA, Wildt DE. 1996. Development to blastocysts of domestic cat oocytes matured and fertilized in vitro after prolonged cold storage. J Reprod Fertil 106: 135-141.

28. Wongsrikeao P, Otoi T, Karja NW, Agung B, Nii M, Nagai T. 2005. Effects of ovary storage time and temperature on DNA fragmentation and development of porcine oocytes. J Reprod Dev 51: 87-97.doi: 10.1262/ jrd.51.87

29. Yang NS, Lu KH, Gordon I. 1990. In vitro fertilization (IVF) and culture (IVC) of bovine oocytes from stored ovaries. Theriogenology 33:352. 